\title{
FUNDO MONETÁRIO INTERNACIONAL
}

\author{
INTERNATIONAL MONETARY FUND
}

\section{FABIO VEIGA DA SILVA ${ }^{1}$ RENATA TONIAL ${ }^{2}$}

\section{RESUMO}

O presente artigo propõe-se a analisar o Fundo Monetário Internacional (FMI), de modo a analisar a atuação deste instituto, bem como verificar suas contribuições eficientes para os países membros. Todavia, antes de adentrar neste tema, num primeiro momento, apresentar-seá um resumo histórico acerca da criação do FMI e sua reformulação diante do contexto mundial, mais especificadamente, desde o marco histórico do ouro-dólar. Por fim, analisar-se-á a atuação prática do FMI, por meio de um caso prático de empréstimo realizado para investimentos, o qual gera uma variedade de atividades voltadas para a criação da infraestrutura física e social, influenciando diretamente na redução da pobreza e para o desenvolvimento sustentável.

PALAVRAS CHAVE: Balanço de pagamento; Variáveis econômicas; Fundo monetário internacional.

\footnotetext{
ABSTRACT

This article aims to analyze the International Monetary Fund (IMF), in order to analyze the performance of this institute, as well as to verify its effective contributions to the member countries. However, before going into this topic, at the outset, I should present a historical

${ }^{1}$ Professor de Direito Empresarial da Universidad de Almería, Espanha (aprovado em concurso PSI), 2020. Foi Professor "venia docendi" da Facultad de Ciencias Jurídicas da Universidad de Las Palmas de Gran Canaria (2019). Foi Professor de Direito Empresarial no Máster en Abogacía da Universidad Europea de Madrid (2016-20172018). Atua como Coordenador do Pós-doutorado em Direito Público da Universidade de Santiago de Compostela (2017-2018-2019-2020).

${ }^{2}$ Mestranda em Direito Empresarial e Cidadania no Centro Universitário UNICURITIBA. Advogada.
} 
summary of the creation of the IMF and its reform in the face of the world context, specifically from the gold-dollar historical milestone. Finally, the IMF's practice practice is analyzed through a case study of investment made for investments, or which generates a variety of activities aimed at the creation of physical and social infrastructure, directly influencing the reduction of economy and sustainable development.

KEYWORDS: Balance of payment; Economic variables; International Monetary Fund.

\section{INTRODUÇÃO}

A proposta do Fundo Monetário Internacional (FMI) é a de promover a estabilidade financeira e a cooperação monetária internacional. Porém, estudar-se-á no presente artigo que há uma corrente que demonstra que o FMI perdeu uma de suas atividades principais, diante da mudança do cenário mundial de regulação do dólar. Além disso, o FMI pretende facilitar o comércio internacional, promovendo empregos e redução da pobreza.

O contexto mundial e brasileiro da adesão ao fundo monetário internacional, criado em 1945, após a II Guerra Mundial, era com o objetivo de levantar as economias abaladas pelas guerras que ficaram em uma situação econômica frágil, bem como de atingir a paz mundial e a prosperidade.

Foi criado em 1944, na denominada conferência de Bretton Woods, feita pela Organização das Nações Unidas, nos Estados Unidos, por 44 (quarenta e quatro) países pactuaram em reestabelecer a situação econômica de um momento pós-guerra, pois o âmbito econômico é o motor que move a economia de um país.

O Fundo é administrado por 189 (cento e oitenta e nove) países membros, todavia, será verificado que tais países possuem participação segundo suas cotas de investimentos, representador por SDR, e quem investe mais, possui maior poder de voto.

Quando se fala em FMI, automaticamente, deve-se ter em mente que está inserido dentro do sistema de balanço de pagamentos, isto é, um registro estatístico de todas as transações (bens, serviços, transferências e fluxos de capital) entre um país e o restante do mundo.

O FMI tem o objetivo principal de ajudar os países com problemas de balanço de pagamento, como o de saldar o balanço quando ele é negativo (gastando mais do que recebendo, 
por exemplo), neste caso o FMI é utilizado para emprestar recursos em situações deficitárias de crônicas.

Após, sanada esta etapa, passar-se-á para a explanação do viés prático, qual seja, demonstrações de empréstimos realizados pelo FMI para investimentos, o qual gera uma variedade de atividades voltadas para a criação da infraestrutura física e social, influenciando diretamente na redução da pobreza e para o desenvolvimento sustentável.

\section{O SISTEMA FINANCEIRO INTERNACIONAL PRÉ BRETTON WOODS, FINALIDADE E REGULAÇÃO}

A ordem econômica tem como finalidade principal suprir as necessidades materiais de uma sociedade, permitindo o bom funcionamento da produção, circulação, distribuição e consumo de bens e serviços.

Neste contexto, a moeda possui grande importância, pois além de servir como meio de troca, possui influência política, econômica e social, pois é o que move as engrenagens do capitalismo globalizado e aproximação dos povos.

Antes de Bretton Woods (1944) não havia um sistema financeiro internacional devidamente institucionalizado. Vale, antes de tudo, conceituar a nomenclatura "sistema financeiro internacional", pois são, resumidamente, medidas que regulamentam as relações financeiras entre Estados, objetivando a interação:

\footnotetext{
Um conjunto de medidas políticas e jurídicas visando a regulamentação e a institucionalização das relações financeiras entre os Estados da sociedade internacional, para instrumentalizar e viabilizar a interação das economias nacionais com a economia internacional, por meio da conversibilidade das taxas de câmbio das moedas nacionais e pela adoção de um padrão monetário com aceitação internacional (MAZZUOLI, 2011).
}

De maneira histórica, anteriormente ao acordo de Bretton Woods existente até os dias de hoje, o que era vigente na época era o "padrão-ouro", adotado antes da I Guerra Mundial, no final do século XIX, o qual possuía três características: i) conversão das moedas nacionais em ouro; ii) entrada e saída de ouro de cada Estado de maneira livre; iii) relação entre a quantidade de ouro em circulação de um determinado estado com o estoque de ouro que dispunha. E, neste contexto, havia a definição de que cada moeda nacional valeria uma quantidade determinada de ouro, de acordo com o estoque de ouro que cada Estado detinha em seu poder. 
Esse sistema, apesar de, na prática, não ter tido todo resultado teórico desejado, conseguiu efetivamente garantir não só a estabilidade nas relações econômicas internacionais, como também estabilidades econômicas internas e um considerável desenvolvimento econômico. (MAZZUOLI, 2011).

Ocorre que, com o advento da I e II Guerra Mundial os Estados entraram em graves crises econômicas, além das geradas pelas guerras, houve a "grande depressão", que foi uma crise de amplitude mundial, conforme afirma a doutrina:

O horror da II Guerra Mundial (1939-1945), acompanhado de circunstâncias fáticas comparativamente piores do que as da I Guerra Mundial, as relações econômicas internacionais e, especialmente, o ideário capitalista ocidental tiveram que ser remodelados em vários aspectos. Terminada a guerra, o mundo ocidental tinha claramente delineado um novo centro de comando econômico, político e militar: os Estados Unidos da América (...) o modelo adotado foi idealizado na Conferência de Bretton Woods, em 1944 nos EUA (MAZZUOLI, 2011).

Portanto, como forma de saída e esperança de uma economia melhor pós-guerra, houve a adesão do sistema de Bretton Woods. Todavia, antes de iniciar uma vasta explanação sobre o tema, é válido contextualizar a situação especificamente do Brasil nesta época, pois estava vigente o contexto do "padrão-ouro", passava-se pelo fim da monarquia, com início da era republicana e pela conturbada "Era Vargas". A sociedade era predominantemente rural, havia a monocultura do café e exportação da borracha. Economicamente, o Brasil já estava independente de Portugal, mas tinha dívida externa com a Inglaterra.

Com o fim da guerra, o Brasil caminhava para a industrialização de sua economia, para a democratização de suas instituições públicas e para a modernização de sua sociedade. Nesse contexto, o país aderiu ao sistema financeiro internacional de Bretton Woods. (MAZZUOLI, 2011).

Portanto, fora este o contexto mundial e brasileiro da adesão ao fundo monetário internacional, criado em 1945, após a II Guerra Mundial, desenvolvido pelo sistema de Bretton Woods, com o objetivo de levantar as economias abaladas pelas guerras que ficaram em uma situação econômica frágil, bem como de atingir a paz mundial e a prosperidade.

Para Brito, embaixador encarregado das primeiras conversações do Brasil no FMI, disse que:

Pela primeira vez grande número de nações submete sua taxa de câmbio à consideração internacional. Iniciando uma nova era em cooperação monetária. A significação máxima desse acontecimento não consiste no anúncio da taxa cambial, mas no fato de que as nações participantes acabam de estabelecer um regime pelo qual se comprometem a promover a estabilidade cambial: a não modificarem a paridade de suas moedas, exceto de conformidade com o acordo sobre 
o Fundo, a de auxiliarem mutuamente a consecução dos objetivos da mesma organização (MRE CONF. No 909, 1946)

Sendo assim, o processo de implementação do FMI nos Bancos Centrais e Ministérios Financeiros foi paulatinamente aplicado conforme se reequilibravam as finanças dos Estados no pós-guerra e também sob o compromisso de cooperação dos países envolvidos. E, o Brasil, em cooperação, não demandou esforços para que as instalações do Banco do Brasil e Ministério da Fazenda pudessem estar compatíveis à instalação das novas 'técnicas' advindas das Nações Unidas, visando a reconstrução das economias nacionais.

O FMI é encarregado de supervisionar o sistema monetário internacional para garantir a estabilidade da taxa de câmbio e incentivar os membros a eliminar as restrições cambiais que impedem o comércio. Além disso, desempenha um papel central em ajudar os países na transição do planejamento para economias voltadas para o mercado.

Com sua sede em Washington/EUA, o FMI iniciou com 28 membros originais e hoje possui 188 países membros. A ideia inicial foi a de criar um fundo comum, onde cada um dos países membros contribuíssem com um valor, cujo valor somado poderia ser emprestado temporariamente, quando um dos países sofressem algum desequilíbrio econômico.

Tinha o objetivo de gerar estabilidade financeira, portanto de supervisionar os outros países com a indicação de políticas públicas de correção, visto que o dinheiro do empréstimo estava condicionado a uma série de regras indicadas pelo FMI.

Os objetivos atuais são o de i) promover a cooperação monetária; ii) promover estabilidade do câmbio; iii) promover o desenvolvimento e expansão do comércio; iv) promover ajuda financeira aos países membros.

Mas como o FMI ajuda os países em dificuldade econômica? O FMI possui uma reserva financeira pessoal, que é fomentada através das cotas que os países membros depositam, então este dinheiro é emprestado a países em dificuldade para que possa reorganizar suas contas públicas, com juros de empréstimos mais baratos do que no mercado financeiro.

As cotas de cada país equivalem a porcentagem que cada membro possui dentro do FMI e é equivalente ao total depositado por este país, essa influência é o peso dos votos que este possui na hora das decisões de investimentos e empréstimos tomados pelo fundo.

Hoje, o FMI é uma organização que trabalha para promover a cooperação monetária global, garantir a estabilidade financeira, facilitar o comércio internacional, promover o alto emprego e o crescimento econômico sustentável e reduzir a pobreza em todo o mundo. Sendo que seu objetivo central é garantir a estabilidade do sistema monetário internacional - o sistema de taxas de câmbio e pagamentos internacionais que permite aos países (e seus cidadãos) 
transacionarem uns com os outros. O mandato do Fundo foi atualizado em 2012 para incluir todas as questões macroeconômicas e do setor financeiro relacionadas à estabilidade global.

Esta garantia da estabilidade do sistema monetário internacional, que tem como missão, é feita por meio do: acompanhando a economia global e as economias dos países membros; empréstimos a países com dificuldades na balança de pagamentos; e dando ajuda prática aos membros.

Além disso, supervisiona o sistema monetário internacional e monitora as políticas econômicas e financeiras de seus 189 países membros. Como parte desse processo, que ocorre tanto em nível global quanto em países individuais, o FMI ressalta possíveis riscos à estabilidade e aconselha sobre os ajustes necessários nas políticas.

Sempre concedendo empréstimos a países membros que enfrentam problemas reais ou potenciais de balanço de pagamentos para ajudá-los a reconstruir suas reservas internacionais, estabilizar suas moedas, continuar pagando pelas importações e restaurar as condições para um forte crescimento econômico, corrigindo problemas subjacentes.

Também trabalha com governos de todo o mundo para modernizar suas políticas econômicas e instituições e treinar seu pessoal. Isso ajuda os países a fortalecer sua economia, melhorar o crescimento e criar empregos

Possui uma equipe de gerenciamento e 17 (dezessete) departamentos que executam seu trabalho nacional, político, analítico e técnico. Um departamento é encarregado de gerenciar os recursos do FMI.

Dentro da equipe, possui um Diretor Administrativo, que é o chefe do pessoal e o Presidente do Conselho Executivo. O Diretor Administrativo é nomeado pelo Conselho Executivo por um período renovável de cinco anos e é auxiliado por um Primeiro Diretor Executivo Adjunto e três Diretores Executivos Adjuntos. Seus funcionários vêm de todo o mundo; são responsáveis perante o FMI, trazendo informação e apoio.

A maioria dos recursos para empréstimos do FMI é fornecida pelos países membros, principalmente através do pagamento de cotas. Estas cotas são um componente central dos recursos financeiros do FMI. A cada país membro do FMI é atribuída uma quota, baseada amplamente em sua posição relativa na economia mundial.

O Direitos de Saque Especiais (SDR) é um ativo de reserva internacional, criado pelo FMI em 1969 para complementar as reservas oficiais de seus países membros. Porém, o ouro continua sendo um ativo importante nas reservas de vários países, e o FMI ainda é um dos maiores detentores oficiais de ouro do mundo. 
Embora as subscrições de cotas dos países membros constituam a principal fonte de financiamento do FMI, o Fundo pode suplementar seus recursos de cotas por meio de empréstimos a países membros que enfrentam problemas reais ou potenciais de balanço de pagamentos para ajudá-los a reconstruir suas reservas internacionais, estabilizar suas moedas, continuar pagando pelas importações e restaurar as condições para um forte crescimento econômico, corrigindo problemas subjacentes.

O FMI também supervisiona o sistema monetário internacional e monitora as políticas econômicas e financeiras de seus 189 países membros. Como parte desse processo, que ocorre tanto em nível global quanto em países individuais, o FMI ressalta possíveis riscos à estabilidade e aconselha sobre os ajustes necessários nas políticas.

Com esse trabalho nos governos de todo o mundo, de modernizar suas políticas econômicas e instituições, de treinamento de pessoal e etc, ajuda os países a fortalecerem sua economia, melhorar o crescimento e criar empregos.

A evolução do FMI se deu juntamente com a economia global ao longo de seus 70 anos de história, permitindo à organização manter um papel central dentro da arquitetura financeira internacional.

Além disso, implementou políticas para garantir que informações significativas e precisas, tanto sobre o próprio papel do FMI na economia global quanto sobre as economias de seus países membros, fossem fornecidas em tempo real a seus públicos globais.

Atualmente os EUA são o maior cotista, estando com $17 \%$ do peso do voto, em comparação, o Brasil encontra-se em $17^{\circ}$ lugar, com $2.5 \%$ de participação.

A forma que é determinado as cotas que cada país deve doar ao FMI, é de acordo com uma análise de seus indicadores econômicos, ou seja, quanto mais forte for a economia de um país, maior será sua cota de contribuição e seu poder de influência dentro do fundo.

Além disso, o FMI possui um centro de pesquisa, chamado "think tank", com especialistas de diversas áreas que estudam sobre economia. Possuem diretrizes de como atingir uma estabilidade econômica.

Os países apenas procuram o FMI quando estão em uma crise gigante, como por exemplo, a crise de responsabilidade fiscal, que é quando um país gasta mais do que ele arrecada; redução de subsídios setoriais/redução de incentivos fiscais a setores específicos, como a redução de imposto a uma empresa específica ou setor, em detrimento dos outros.

Porém, críticos argumentam que as diretrizes impostas pelo FMI como pré-requisitos para o empréstimo do dinheiro são desgastantes para serem aplicadas e enfrentadas pelos países membros, visto que muitos dos países ricos não seguiram esses princípios pra ficarem ricos, e 
o FMI impõe aos países pobres. Acreditam também que o FMI é parte de uma grande conspiração internacional para os ricos permanecerem no poder.

\section{BALANÇO DE PAGAMENTOS}

Quando se fala em FMI, automaticamente, deve-se ter em mente que está inserido dentro do sistema de balanço de pagamentos, isto é, um registro estatístico de todas as transações (bens, serviços, transferências e fluxos de capital) entre um país e o restante do mundo.

Balanço de pagamentos é o nome dado ao registro contábil de todas as transações econômicas e financeiras de um determinado país com seus similares no mundo todo. É composto por duas contas principais, que são: a) conta corrente ou transações correntes, que é composta pelo saldo da balança comercial, balança de serviços e transferências unilaterais. É na conta corrente que são registrados as transferências de bens e serviços e as doações recebidas ou dadas sem existência de uma contrapartida. b) conta capital ou financeira, que destina-se a agrupar os investimentos diretos (tanto os de autoria de brasileiros no exterior como os de estrangeiros no Brasil), investimentos em carteira (são os investimentos feitos em ações, aplicações no mercado financeiro, e similares) (INFOESCOLA, 2008).

O FMI tem o objetivo principal de ajudar os países com problemas de balanço de pagamento, como o de saldar o balanço quando ele é negativo (gastando mais do que recebendo, por exemplo), neste caso o FMI é utilizado para emprestar recursos em situações deficitárias de crônicas.

Os países membros tem direito a serem socorridos quando tiverem com problema de balanço de pagamento. Porém, existe uma sistemática onde quem deposita mais, pode resgatar mais e ter mais direito de voto, ou seja, a retirada é feita conforme a capacidade do país membro.

Um membro pode emprestar facilmente $25 \%$ dos seus recursos depositados, todavia, se quiser mais dinheiro do que contribui, existe uma condicionalidade junto a este empréstimo, tendo em vista alguns fatores: i) os juros são menores, por esta fato compensa emprestar do FMI; ii) os recursos são escassos, pois se todos os países retirarem, acaba com o fundo; iii) por isso é preciso que o fundo tenha proteção, que é a segurança de que o determinado país seguirá 
suas orientações para recuperar seu dinheiro. Portanto, passa-se agora a analisar tais condicionalidades.

O fundo tem uma equipe de economistas que vão até o país e examinam a situação econômica e empresta sujeito a regularização da situação, para ter como devolver o dinheiro. Esta chamada é feito por meio de uma "carta de intenção", que é um volume com orientações, prazos e percentuais.

Essas condicionalidades envolvem variáveis econômicas, e dentro dessas variáveis econômicas existe um modelo "macroeconômico" que o FMI usa como uma meta para chegar a quais variáveis precisam ser perseguidas para redução/melhoria.

O Produto Interno Bruto (PIB) é consumido ou investido ou o governo usa ou é exportado/importado. O PIB é o valor que se produz, e isto gera renda que vai ser gasta em consumo, em poupança e em tributo que se arrecada ao governo.

Deve-se entender que o que movimenta esta máquina são as importações, exportações de bens e serviços. Logo, se as importações são superiores as exportações, o saldo das transações correntes está negativo.

Outro fator determinante para movimentar a máquina é a situação dos gastos do governo frente aos impostos arrecadados, logo, se isto ocorrer, o país tem um déficit público.

Por fim, outro fator é quando o investimento dos empresários são maiores que a poupança, que são os recursos existentes, pois quando vai se investir em algo retira-se da poupança, então todo investimento acima da poupança ocorre um excesso de investimento, portanto ou cai o investimento ou investe em política públicas ao incentivo ao aumento da poupança.

São estudos em cima destas diretrizes que o FMI utiliza para reorganizar e implantar medidas e melhorias a seus países membros.

\section{CASOS PRÁTICOS DE EMPRÉSTIMO PARA INVESTIMENTO ESPECÍFICO}

Os empréstimos para investimentos específicos (EIE) apoiam a criação, recuperação e conservação da infra-estrutura econômica, social e institucional. Além disso, podem financiar serviços de consultoria e programas de gerenciamento e treinamento.

Utiliza-se o EIE para uma ampla variedade de projetos, tendo em vista sua flexibilidade. O qual contribui para garantir a viabilidade técnica, financeira, econômica, ambiental e 
institucional de investimentos específicos, em prol de políticas que afetam a produtividade do investimento

Este setor contribui para a criação, recuperação e conservação da infraestrutura econômica, social e institucional. Além disso, podem financiar serviços de consultoria e programas de gerenciamento e treinamento. Neste sentido, evidencia-se o caso prático ocorrido na Tailândia:

TAILÂNDIA: PROJETO DE INVESTIMENTO SOCIAL MONTANTE DO EMPRÉSTIMO: US\$ 300 milhões do BIRD. DESCRIÇÃO: Este projeto responde à crise financeira e econômica no leste da Ásia mediante apoio à rápida criação de empregos e a provisão de serviços sociais essenciais aos desempregados e aos pobres. Apoia também a prestação de serviços a partir da base através de financiamento de iniciativas de desenvolvimento localmente identificadas e administradas, do incentivo à descentralização, da capacitação de recursos humanos locais e do desenvolvimento comunitário (BANCO MUNDIAL, 2001).

Outra variável do Empréstimo para Investimento é a de Manutenção Setorial, na qual existe a concentração de programas de gastos públicos em determinados setores. Seu objetivo é alinhar os gastos, as políticas e o desempenho setorial com as prioridades de desenvolvimento de um país, ajudando a criar um equilíbrio adequado entre novos investimentos de capital, recuperação, reconstrução e manutenção. Tem-se como exemplo, a Indonésia:

INDONÉSIA: PROJETO DE RODOVIAS NA REGIÃO DE SUMATRA MONTANTE DO EMPRÉSTIMO: US\$ 234 milhões do BIRD. DESCRIÇÃO: O projeto apoia o esforço do governo de incentivar o desenvolvimento regional eficiente, equitativo e ambientalmente sustentável. O seu objetivo é aumentar a eficiência e a acessibilidade dos transportes dentro das oito províncias de Sumatra, mediante a integração e o fortalecimento do planejamento e da gestão da infraestrutura de transportes (BANCO MUNDIAL, 2001).

Existem também os Empréstimo para Programa Adaptável, o qual gera melhorias de desenvolvimento a longo prazo, pois aproveitam as experiências de empréstimos realizados anteriormente. Exemplo, o caso da Índia: 


\section{ÍNDIA: EMPRÉSTIMO PARA PROGRAMA DE REESTRUTURAÇÃO DO}

SETOR ELÉTRICO MONTANTE DO EMPRÉSTIMO: US\$ 210 milhões do BIRD DESCRIÇÃO: Este projeto, primeiro de uma série, faz parte de um programa adaptável que, nos próximos oito anos, ajudará a transformar o setor elétrico de Andhra Pradesh - atualmente um grande dreno no orçamento do estado - em fornecedor de recursos para setores prioritários (BANCO MUNDIAL, 2001).

Outra flexibilidade é o Empréstimo para Aprendizado e Inovação, que permite o apoio a pequenos projetos-piloto de investimento e de fortalecimento da capacidade que, se tiver êxito, pode tornar-se um projeto maior. Apesar de ser menos expressivo, visa garantir oportunidades e novos empréstimos. Exemplo em Moldova:

\section{MOLDOVA: PROJETO DE FINANCIAMENTO RURAL MONTANTE DO} EMPRÉSTIMO: US\$ 5 milhões da AID. DESCRIÇÃO: Este projeto visa o desenvolvimento de um sistema bancário de cooperativas rurais para prestar serviços financeiros a pequenos agricultores e empresários rurais. O projeto (1) cria associações de poupança e empréstimos (APEs) e prepara seus membros, com assistência da Aliança de Micro-finanças de Moldova; (2) cria um organismo regulador para as APEs; (3) fortalece a Corporação de Financiamento Rural; e (4) financia uma linha de crédito rural para APEs (BANCO MUNDIAL, 2001).

Existe também o Empréstimo para Assistência Técnica, o qual é usado para fortalecer a capacidade institucional no país mutuário. Tal empréstimo realiza esquemas organizacionais, métodos de formação de quadros de pessoal e recursos técnicos, físicos e financeiros em órgãos chaves. Exemplo:

PERU: PROJETO SOBRE DIREITOS DE PROPRIEDADE URBANA MONTANTE DO EMPRÉSTIMO: US\$ 38 milhões do BIRD. DESCRIÇÃO: Este projeto tem por objetivo assegurar direitos formais de propriedade em núcleos urbanos predominantemente pobres. $\mathrm{O}$ empréstimo financia o registro de quase 960.000 propriedades, das quais 800.000 deverão receber títulos individuais. O processo de regularização deverá beneficiar os 4 milhões de pessoas - um quarto da população total - que vivem em torno da linha de pobreza (BANCO MUNDIAL, 2001). 
Empréstimo de Intermediação Financeira Proporcionam a instituições financeiras locais recursos de longo prazo para financiar as necessidades reais de investimento setorial. As instituições financeiras assumem o risco de crédito de cada subprojeto. Um exemplo é o ocorrido na Lituânia:

\section{LITUÂNIA: PROJETO DO SETOR EMPRESARIAL E FINANCEIRO MONTANTE DO EMPRÉSTIMO: US\$ 25 milhões do BIRD. DESCRIÇÃO:} Este projeto apoia a reforma governamental no setor financeiro e a provisão de financiamento em apoio ao desenvolvimento de empresas privadas e privatizadas. Proporciona recursos financeiros e assistência técnica para aprimorar (1) a capacidade do sistema bancário de distribuir recursos financeiros e (2) a capacidade das empresas para preparar planos de financiamento (BANCO MUNDIAL, 2001).

Empréstimo de Emergência para Recuperação Apoiam a restauração de ativos e níveis de produção imediatamente após uma ocorrência extraordinária - como uma guerra, distúrbio civil ou catástrofe natural - que transtorna gravemente a economia do mutuário. São usados também para fortalecer a gestão e implementação do esforço de reconstrução e para aperfeiçoar tecnologias de resistência a catástrofes e sistemas de alerta destinados a prevenir ou minorar o impacto de emergências futuras. Exemplo:

REPÚBLICA DOMINICANA: PROJETO DE OPERAÇÕES DE EMERGÊNCIA MONTANTE DO EMPRÉSTIMO: US\$ 111 milhões do BIRD DESCRIÇÃO: Este projeto (1) ajuda a manter o crescimento em setores essenciais da economia; (2) apoia a reconstrução e recuperação de infraestruturas sociais e econômicas essenciais danificadas ou destruídas pelo furacão Georges; e (3) fortalece a capacidade do país para se preparar e dar respostas a futuras emergências causadas por catástrofes naturais. Um componente de desembolso rápido financia as importações necessárias para a agricultura e para a reconstrução, e um componente de investimento financia a recuperação de infraestrutura pública essencial. O projeto inclui também atividades de fortalecimento institucional. Sua aprovação é mais rápida e menos burocrática (BANCO MUNDIAL, 2001). 
Empréstimos para Ajuste e Outros Empréstimos Não Vinculados a Projetos, proporcionam assistência de desembolso rápido a países com necessidades de financiamento externo para apoiar reformas estruturais em um setor ou em toda a economia. Apoiam as mudanças institucionais e de política necessárias para criar um clima favorável ao crescimento sustentado e equitativo. Com o tempo, passaram a se concentrar mais na reforma das estruturas, do setor financeiro e da política social, assim como a melhoria da gestão de recursos no setor público. Como por exemplo o Empréstimo para Ajuste Estrutural, que apoia reformas que promovam o crescimento, o uso eficiente de recursos e um balanço de pagamentos sustentável a médio e longo prazo. Exemplo:

MALÁSIA: EMPRÉSTIMO PARA RECUPERAÇÃO ECONÔMICA E O SETOR SOCIAL MONTANTE DO EMPRÉSTIMO: US\$ 300 milhões do BIRD DESCRIÇÃO: Este projeto apoia o programa de medidas cautelares do governo para (1) minimizar a retração da atividade econômica depois da crise regional de 1997-98; (2) expandir as redes de assistência social para proteger os pobres e os quase pobres contra os efeitos adversos da crise; e (3) proteger os investimentos em recursos humanos. Apoia também reformas de políticas destinadas a promover um crescimento vigoroso e sustentável (BANCO MUNDIAL, 2001).

MARROCOS: EMPRÉSTIMO PARA DESENVOLVIMENTO DA POUPANÇA CONTRATUAL MONTANTE DO EMPRÉSTIMO: US\$ 150 milhões do BIRD. DESCRIÇÃO: Este projeto objetiva melhorar o acúmulo de poupança a longo prazo, estimular a sua alocação para investimentos produtivos privados e garantir a sustentação, a longo prazo do sistema de aposentadorias do país. Enfoca a reforma das instituições de poupança contratual, inclusive companhias de seguros, instituições de poupança e o sistema de pensões (BANCO MUNDIAL, 2001).

Já o Empréstimo Especial para Ajuste Estrutural, atua nas reformas estruturais e sociais efetuadas por mutuários com bons antecedentes de crédito à beira de uma possível crise ou já em crise e com necessidades excepcionais de financiamento externo. Estes empréstimos ajudam os países a evitar a crise ou, se esta ocorrer, a minorar os seus impactos econômicos e sociais adversos. Exemplo: 


\section{ARGENTINA: EMPRÉSTIMO ESPECIAL PARA AJUSTE ESTRUTURAL}

MONTANTE DO EMPRÉSTIMO: US\$ 2,52 bilhões do BIRD DESCRIÇÃO: Este empréstimo, conjugado com o Empréstimo Especial de Apoio ao Mecanismo de Recompra, ajuda o país na continuação de seus esforços para transformar a sua economia e proteger os resultados já obtidos. O programa tem caráter preventivo, visando a minorar os efeitos nocivos da instabilidade financeira internacional sobre a economia e sobre os grupos vulneráveis. O empréstimo ajuda o governo a atender às suas necessidades de divisas, permitindo-lhe assim manter o seu foco na reforma a longo prazo (BANCO MUNDIAL, 2001).

Empréstimo para Redução da Dívida ajuda países elegíveis altamente endividados a reduzir a dívida comercial e o serviço da dívida a um nível tolerável, como parte de um plano de financiamento, a médio prazo, em apoio ao crescimento sustentável. O foco do empréstimo é a racionalização da dívida bancária comercial externa do país, seja convertendo-a em instrumentos com juros mais baixos, seja recomprando-a com desconto. Exemplo desta situação:

PANAMÁ: PROJETO DE REDUÇÃO DA DÍVIDA E DO SERVIÇO DA DÍVIDA MONTANTE DO EMPRÉSTIMO: US\$ 30 milhões do BIRD. DESCRIÇÃO: Esta operação teve por finalidade facilitar o desenvolvimento ao ajudar o país a restabelecer o seu crédito. Ela ajudou o governo a implementar a redução da dívida e do serviço da dívida, a consolidar o equilíbrio fiscal e as reformas estruturais e a normalizar as relações com os credores comerciais (BANCO MUNDIAL, 2001).

\section{CONCLUSÃO}

Um prejuízo advindo de uma má gestão em um país pode comprometer as atividades da empresa como um todo, gerando desequilíbrio financeiro e má reputação, pode abalar significativamente toda a estrutura não apenas financeira, mas de uma sociedade/nação.

Quando se fala em FMI, automaticamente, deve-se ter em mente que está inserido dentro do sistema de balanço de pagamentos, isto é, um registro estatístico de todas as transações (bens, serviços, transferências e fluxos de capital) entre um país e o restante do mundo. 
O FMI tem o objetivo principal de ajudar os países com problemas de balanço de pagamento, como o de saldar o balanço quando ele é negativo (gastando mais do que recebendo, por exemplo), neste caso o FMI é utilizado para emprestar recursos em situações deficitárias de crônicas.

O FMI, surge, então, com o papel de otimizar o desempenho das políticas públicas de um país. Vale dizer, portanto, que a preocupação do FMI é agregar valor ao negócio, aumentando a confiabilidade e os olhares dos investidores a ela, por meio de uma boa gestão e passos equilibrados, possibilitando a expansão e crescimento.

O contexto mundial e brasileiro da adesão ao fundo monetário internacional, criado em 1945, após a II Guerra Mundial, era com o objetivo de levantar as economias abaladas pelas guerras que ficaram em uma situação econômica frágil, bem como de atingir a paz mundial e a prosperidade.

Foi criado em 1944, na denominada conferência de Bretton Woods, feita pela Organização das Nações Unidas, nos Estados Unidos, por 44 (quarenta e quatro) países pactuaram em reestabelecer a situação econômica de um momento pós-guerra, pois o âmbito econômico é o motor que move a economia de um país.

Em síntese, o FMI tem como um de seus objetivos, por meio do planejamento, administração e gestão consciente, se esquivar de arcar com danos provenientes dos riscos gerados à sociedade, e sua maior proposta é a de promover a estabilidade financeira e a cooperação monetária internacional, facilitando o comércio internacional, promovendo empregos e redução da pobreza.

Por meio dos casos práticos vislumbrados, realizado para investimentos, notou-se que gerou extrema infraestrutura física e social aos países beneficiados, influenciando diretamente na redução da pobreza e no desenvolvimento sustentável.

\section{REFERÊNCIAS}

BRITO, Octavio do Nascimento Brito. De Brito a Francisco Alves do Santos Filho. (MRE). Telegrama. Washington ao MRE, conf. n 909, 1946.

MAZZUOLI, Valério de Oliveira. Curso de Direito Internacional Público. 5 ed. São Paulo: Editora dos Tribunais, 2011, p. 24 a 28.

BRASIL. Constituição da República Federativa do Brasil. Brasília, DF: Senado Federal: Centro Gráfico, 1988. Artigos 170 e 192; 
INFORME ECONÔMICO. Balanço de Pagamentos. Disponível em: <http://informeeconomico.com.br/2008/08/18/balanco-de-pagamentos.html>. Acesso em 09/09/2019.

BANCO MUNDIAL. Instrumentos de Empréstimos do Banco Mundial: política de operações e serviços aos países. Páginas 05 a 24 . Disponível em: $<$ http://siteresources.worldbank.org/BRAZILINPOREXTN/Resources/3817166-

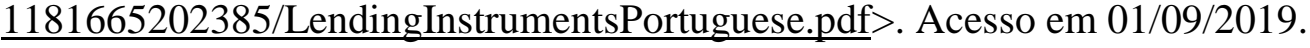

LUPI, Andre Lipp Pinto Basto; MACEI, Demétrius Nichele; MOSER, Manoela Pereira. Fundo Monetario Internacional e os Acordos de Standby. Revista Jurídica, [S.1.], v. 4, n. 53, p. 402 419, dez. 2018. ISSN 2316-753X. Disponível em: $<$ http://revista.unicuritiba.edu.br/index.php/RevJur/article/view/3225/371371741 >. Acesso em: 25 abr. 2020. doi:http://dx.doi.org/10.21902/revistajur.2316-753X.v53i4.3225.

VALE, Sergio R.. Macroeconomia e governança global: um casamento incompleto. Relações Internacionais no Mundo Atual, [S.1.], v. 1, n. 21, dez. 2018. ISSN 2316-2880. Disponível em: 〈http://revista.unicuritiba.edu.br/index.php/RIMA/article/view/3197/371371721>. Acesso em: 25 abr. 2020. doi:http://dx.doi.org/10.21902/Revrima.v1i24.3197. 